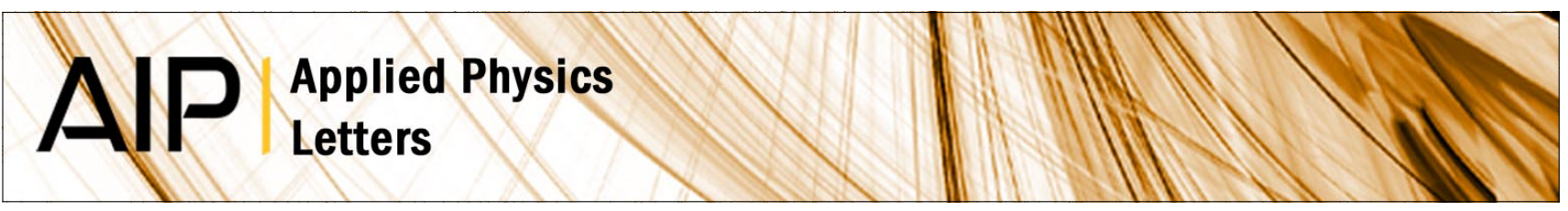

\title{
Nanostructure of sol-gel films by x-ray specular reflectivity
}

S. L. Morelhão, G. E. S. Brito, and E. Abramof

Citation: Appl. Phys. Lett. 80, 407 (2002); doi: 10.1063/1.1436271

View online: http://dx.doi.org/10.1063/1.1436271

View Table of Contents: http://apl.aip.org/resource/1/APPLAB/v80/i3

Published by the American Institute of Physics.

Additional information on Appl. Phys. Lett.

Journal Homepage: http://apl.aip.org/

Journal Information: http://apl.aip.org/about/about_the_journal

Top downloads: http://apl.aip.org/features/most_downloaded

Information for Authors: http://apl.aip.org/authors

\section{ADVERTISEMENT}

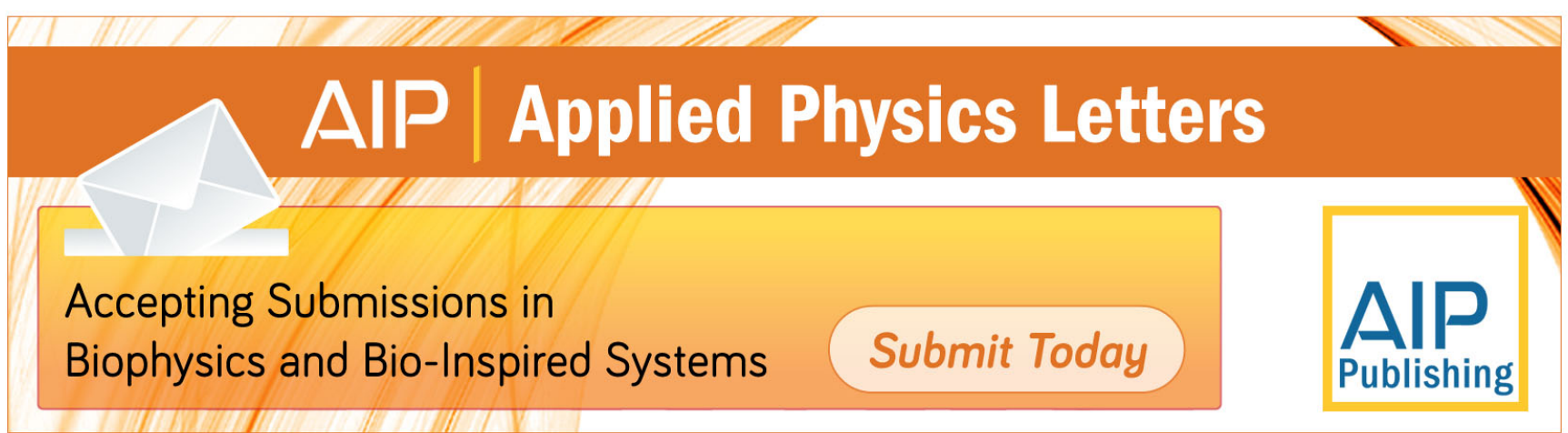




\title{
Nanostructure of sol-gel films by $x$-ray specular reflectivity
}

\author{
S. L. Morelhão a) and G. E. S. Brito \\ Instituto de Física, USP, CP 66318, 05315-970 São Paulo, SP, Brazil \\ E. Abramof \\ Instituto Nacional de Pesquisas Espaciais, LAS, CP 515, 12201-970 São José dos Campos, SP, Brazil
}

(Received 4 May 2001; accepted for publication 28 November 2001)

\begin{abstract}
Recently, several studies have been carried out on sol-gel films for optical applications, mostly motivated by the quickness and low cost of the film preparation process. In order to preserve the coherence properties of the light, improvements in the current quality of such films are necessary as well as appropriated techniques for structural characterization and quality control. X-ray specular reflectivity could be one of such techniques, but it is limited by the complexity of the internal nanostructure of the films. In this work, we have developed a procedure to extract the exact density profile of sol-gel films, and applied it to analyze a sol-gel derived $\mathrm{Er}_{2} \mathrm{O}_{3}$ film. (C) 2002 American Institute of Physics. [DOI: 10.1063/1.1436271]
\end{abstract}

Sol-gel films have been widely investigated for optical applications due to their very low cost and fast preparation process. ${ }^{1,2}$ Layered films of different density and thickness can easily produce waveguides for visible light $^{3-7}$ as well as for hard $\mathrm{x}$ rays. ${ }^{8}$ In high-brilliance synchrotron radiation sources, $\mathrm{x}$-ray waveguides have become an important optical device that can lead to new developments in $\mathrm{x}$-ray microscopy ${ }^{9}$ and characterization techniques with submicroscale resolution. ${ }^{10}$ Waveguides are basically composed of a multilayer structure including a light material onto a heavier one, whose waveguidance efficiency is strongly enhanced by overcoating the top surface with a very thin layer as dense as the bottom one. For most applications, coherence of the waveguided $\mathrm{x}$ rays is crucial. Interface roughness does generate incoherent scattering that compromises the coherence of the beam exiting the waveguide and, at values above a few nanometers, the roughness can destroy the guided modes.

The detailed structure of sol-gel films is still under investigation. ${ }^{11}$ The dynamics of nanoparticles coalescence during firing, or heat treatment, can generate abrupt density variations and porosity inside a single film. Both features contribute to reduce the lateral coherence length, and they would give rise to a sort of internal roughness that, in terms of incoherent scattering, plays the same role as interface roughness. Then, at the present status of film preparation, it is evident that a characterization tool is needed for analyzing the structure of the films at a nanometer scale. It would provide the necessary information to improve the procedures for producing high quality sol-gel films. Density profile and internal roughness, besides thickness, are the most important parameters to be extracted and correlated to the variables of the preparation procedure, such as coating speed and firing temperature.

$\mathrm{X}$-ray specular reflectivity is a nondestructive characterization method applied to a large variety of thin-film materials. For laterally uniform films, grazing incidence reflectivity

\footnotetext{
a) Author to whom all correspondence should be addressed; electronic mail: morelhao@if.usp.br
}

measurements can be applied equally effectively to single crystal, polycrystalline, or amorphous films. The specular scattering in the region just above the critical angle contains information not only on the longitudinal electron density and thickness of submicron films, but also on the surface and interface roughness at atomic scale. Since, through a simple inverse transformation of the scattered intensity, is not possible to obtain all the film parameters, the adopted approach for the interpretation of reflectivity data has been the simulation of the scattering from a model structure and adjustment of parameters until a good fit is obtained. Besides the difficulties involved in this last step, i.e., in the parameters adjustment, the technique is limited by the preliminary knowledge of the structure of the film. Exceptions are single layers with uniform density and thickness, which are extracted directly from the curves. Otherwise, the best possible fit will be satisfactory only when the correct model has been assumed, i.e., a model that has a number of adjustable parameters that describe the actual structure of the film. For sol-gel films, the uniform single-layer model is useful only to estimate the thickness and average (or apparent) density. ${ }^{11}$ In this letter, we are proposing an adjustable model structure able to extract the longitudinal density profile of sol-gel films from the x-ray specular curve.

Figure 1 shows the experimental $\mathrm{x}$-ray reflectivity curve (open circles) of a three-layer film deposited by dip coating on a glass plate in a sol-gel solution containing $\mathrm{Er}_{2} \mathrm{O}_{3}$ nanoparticles. Each single-layer dip was followed by firing at $500{ }^{\circ} \mathrm{C}$ for a few minutes in order to eliminate the gel and the organic cap of the nanoparticles. The detailed process for producing such films has been described elsewhere. ${ }^{12}$ The grazing incidence $\mathrm{x}$-ray reflectivity measurements were performed in a high-resolution x-ray diffractometer (Philips $\mathrm{X}$ 'Pert-MRD) equipped with a $\mathrm{Cu} \mathrm{X}$-ray tube in the line focus. The primary optics (for the incident beam) was composed of a Soller slit, a $1 / 32^{\circ}$ divergence slit, and an attenuator. For the secondary optics (reflected beam) we used, before the detector, a parallel beam collimator, a $0.1 \mathrm{~mm}$ antiscatter slit and a flat crystal graphite monochromator. Before starting measurement, the sample height and the goni- 


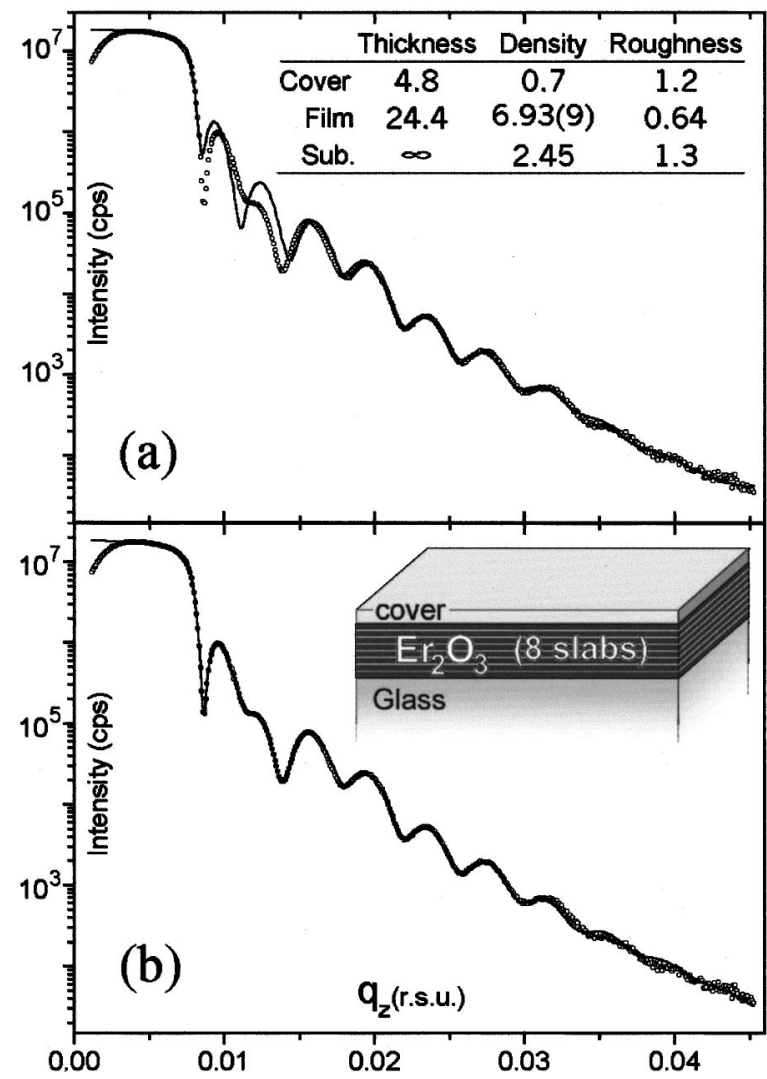

FIG. 1. X-ray specular reflectivity curves from the erbium oxide sol-gel film. The experimental curve (open circle) is compared to the best fitting curves (straight lines) obtained with the M8 (a) and M8r (b) models. An illustration of these eight-slab models is shown in the bottom figure (b). The density (in $\mathrm{g} / \mathrm{cm}^{3}$ ), thickness and roughness (in $\mathrm{nm}$ ) values extracted from M8 are given in the inset, top figure (a). Those extracted from M8r are given in Fig. 2. The single-layer model M1 gives practically the same parameter values as those extracted from the M8 model.

ometer zero points $(2 \theta$ and $\omega=0)$ were precisely adjusted. The reflectivity spectra were recorded by a longitudinal scan in the reciprocal space, $\omega / 2 \theta$ scan. The attenuator is used for angles lower than a predefined angle to avoid the detector damage due to a very intense incident radiation. The attenuator factor is automatically computed during the measurement, allowing a dynamical scale of eight orders of magnitude.

In order to fit the experimental curve in Fig. 1, three possible models were considered for the structure of the $\mathrm{Er}_{2} \mathrm{O}_{3}$ film: the single-layer model (M1), the multislab model (M8) and the multislab model with roughness at the interfaces between each slab (M8r). A cover layer of composition $2 \mathrm{H}: 1 \mathrm{C}: 2 \mathrm{~N}: 5 \mathrm{O}$, which might be present due to air contamination, has been added to all models, and it has significantly improved the fitting quality. The differential evolution algorithm, ${ }^{13}$ a genetic algorithm, allowed to adjust the parameters of the models until the reflectivity simulation program ${ }^{14}$ generates the best possible fit with the experimental data. The fitting evolution is driven by mean-absolute error of the log-transformed data. In the Parratt's recursionrelation formalism ${ }^{15}$ employed by the simulation program, the effects of roughness are taken into account by reducing the Fresnel reflection amplitude, $r_{F}$, of each interface. The expression for such reduction at the $j$ th interface, between slabs $j$ and $j+1$, is given ${ }^{16}$ by $\mathrm{r}(j)=\mathrm{r}_{\mathrm{F}}(j)$

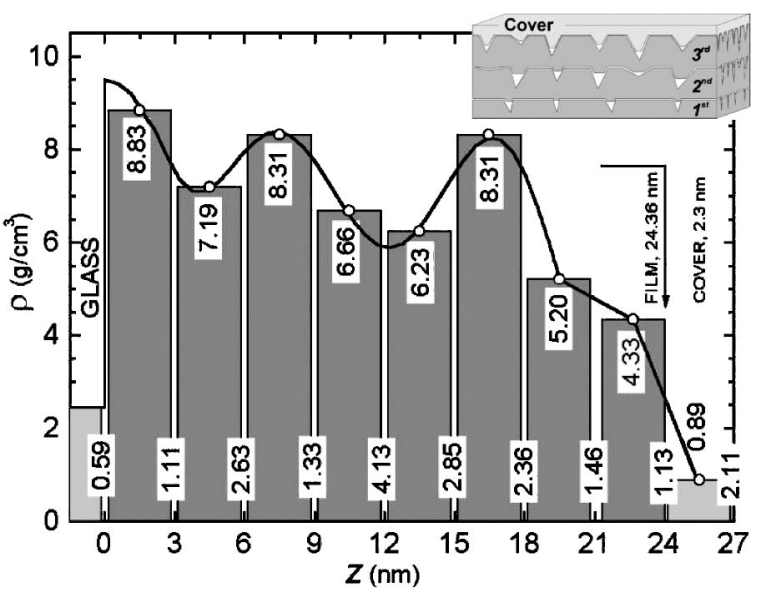

FIG. 2. Nanostructure of the erbium oxide sol-gel film determined by fitting the x-ray specular reflectivity curve in Fig. 1(b). The fitting was obtained with the M8r model where the film thickness was divided into eight slabs, represented by the dark gray bars, plus a cover layer of composition $2 \mathrm{H}: 1 \mathrm{C}: 2 \mathrm{~N}: 5 \mathrm{O}$ due to air contamination. The bars height stands for the density values (in $\mathrm{g} / \mathrm{cm}^{3}$ ) written at the top, and the number in between bars are the interface roughness (in $\mathrm{nm}$ ) considered in the model. The longitudinal density profile (straight line) is obtained by polynomial interpolation. One possible explanation for this density profile is schematized in the inset, where the surface after the first, second, and third dipping procedures is located around $z$ equal to $6 \mathrm{~nm}, 15 \mathrm{~nm}$, and $24 \mathrm{~nm}$, respectively.

$\times \exp \left[-2 k_{2, j} k_{2, j+1} \sigma_{j}^{2}\right]$, where $\sigma_{j}$ stands for the Gaussian width of the interface due to roughness, and $k_{z, j}$ is the longitudinal component of the wavevector in the slab $j$.

The single-layer model M1 shows that the $\mathrm{Er}_{2} \mathrm{O}_{3}$ film is about $24 \mathrm{~nm}$ thick with a density of $6.93 \mathrm{~g} / \mathrm{cm}^{3}$. By dividing this thickness into eight slabs, we came out with the M8 model, which has seven slabs of $3 \mathrm{~nm}$ plus one last slab of adjustable thickness. Since no roughness is allowed for the seven first slabs, only the density values are adjustable parameters for these slabs. The best fit obtained with this model is shown in Fig. 1(a), and it is practically identical to the previous one. The average density of the slabs is also 6.93 $\mathrm{g} / \mathrm{cm}^{3}$, with a deviation from one slab to another not larger than $1.3 \%\left( \pm 0.09 \mathrm{~g} / \mathrm{cm}^{3}\right)$. The other parameters are given in the inset of Fig. 1(a). However, the remarkable good fitting in Fig. 1(b) could only be achieved with the M8r model, which is the same as M8 but with seven new adjustable parameters, standing for the roughness at the interfaces between adjacent slabs. Other models with less than eight slabs did not succeed in fitting the experimental data, and that is the reason for having the film thickness divided into eight slabs in both M8 and M8r models. The exact structure of the film determined by the M8r model is shown in Fig. 2. The final density values of the slabs do not differ from those in Fig. 2 by more than $2.5 \%$, independently from their initial values (in the range $4-10 \mathrm{~g} / \mathrm{cm}^{3}$ ). On the other hand, the sensitivity of the fit to the roughness values depends on the density variation throughout each interface. For instance, the fit deviation bounces $5 \%$ if the roughness at $z=0(|\Delta \rho / \rho|$ $=14.768)$ changes only $2 \%$. But at $z=12 \mathrm{~nm}(|\Delta \rho / \rho|$ $=0.065)$, a $32 \%$ difference in the roughness value would be necessary to obtain the same deviation. Physically, it means that the total scattering has low sensitivity to roughness at interfaces with small Fresnel reflection coefficient, i.e., at 
those interfaces between layers with nearly the same densities.

The most important feature in the M8r model is that, by introducing roughness at the interfaces between adjacent slabs, the model was able to simulate the effects of the internal roughness in the film. Since this internal roughness stands for the reflectivity reduction, it demonstrates that some amount of diffuse scattering is generated inside the film. Otherwise, the M8 model would have succeeded in fitting the experimental curve and extracting the longitudinal density profile. The M8r model is able to extract the density profile, which is more complex than just the average density, only when the reflectivity reduction is properly taken into account by the internal roughness. The two minima of the density profile observed in Fig. 2, around 4.5 and $12 \mathrm{~nm}$, are correlated to the number of dipping procedures (three in this case) used to prepare the film. After each single-layer deposition, the fired layer has a lower density towards the surface, and subsequent overcoating and heating did not restore the density of the previous surface. The first single-layer has a thickness of about $6 \mathrm{~nm}$ and each subsequent layer adds approximately $9 \mathrm{~nm}$ to the total thickness. Then, a length scale resolution of $3 \mathrm{~nm}$, the slab thickness, was necessary to resolve the profile. The presence of a low-density cover layer has been observed in other sol-gel films. ${ }^{11}$ Although the thickness of this layer $(2.3 \pm 0.5 \mathrm{~nm}$; hereafter the errors are estimated by fit deviation bouncing 5\%) is still larger than the one expected for a contamination layer due to absorption of air species, it should be noted that this thickness is significantly smaller than the value $(4.8 \pm 1.0 \mathrm{~nm})$ estimated by using the M1 or M8 models [inset of Fig. 1(a)]. Moreover, the roughness value at the surface of the multilayer film has increased when the correct model was used. This is a critical value for sol-gel derivated waveguide films because it will be the interface between two compounds of very different densities. For instance, in an hypothetical $\mathrm{Er}_{2} \mathrm{O}_{3} / \mathrm{SiO}_{2} /$ $\mathrm{Er}_{2} \mathrm{O}_{3} \mathrm{x}$-ray $(8 \mathrm{keV})$ waveguide, a significant decrease in the intensity of the guided modes is observed for interface roughness values above $1.2 \mathrm{~nm}$. At $2.0 \mathrm{~nm}$, the modes are completely destroyed. These data were deduced from the same reflectivity simulation program ${ }^{14}$ used as mentioned.

In summary, we have demonstrated that detailed density profiles of single compound sol-gel films can be extracted from x-ray specular reflectivity curves. The calculated spec- trum can be precisely adjusted to the measured one by using a multislab model with internal roughness, i.e., with roughness at each slab interface. The model takes into account the diffuse scattering generated inside the film, which is an evidence of internal porosity. The density profile extracted by the appropriated model allows us to conclude that the shrinkage during firing introduces some rifts at each single-layer interface as well as at the external surface, as schematized in the inset of Fig. 2. Characterization of sol-gel films with specular reflectivity assuming a single-slab film also leads to imprecise values of the cover-contamination layer thickness and surface roughness.

The authors would like to thank the Brazilian founding agencies FAPESP (Proc. number 99/00273-8) and CNPq (Proc. numbers 301617/95-3). They also thank Dr. Keith Bowen (Bede Scientific Instruments Ltd.) for the REFS_mercury software.

${ }^{1}$ C. J. Brinker and G. W. Scherer, Sol-Gel Science: The Physics and Chemistry of Sol-Gel Processing (Academic, New York, 1990); L. F. Francis, Mater. Manuf. Processes 12, 963 (1997).

${ }^{2}$ P. K. Biswas, D. Kundu, and D. Ganguli, J. Mater. Sci. Lett. 6, 14811 (1987).

${ }^{3}$ A. Bahtat, M. Bouazaoui, B. Mahtat, and J. Mugnier, Opt. Commun. 111, 55 (1994).

${ }^{4}$ M. A. Fardad, H. Luo, Y. Beregovski, and M. Fallahi, Opt. Lett. 24, 460 (1999).

${ }^{5}$ K. M. Chen, A. W. Sparks, H. C. Luan, D. R. Lim, K. Wada, and L. C. Kimerling, Appl. Phys. Lett. 75, 3805 (1999).

${ }^{6}$ C. Coutier, M. Audier, J. Flick, R. Rimet, and M. Langlet, Thin Solid Films 372, 177 (2000).

${ }^{7}$ H. Rigneault, C. Amra, S. Robert, C. Begon, F. Lamarque, B. Jacquier, P. Moretti, A. M. Jurdyc, and A. Belarouci, Opt. Mater. 11, 167 (1999).

${ }^{8}$ S. Lagomarsino, A. Cedola, S. Di Fonzo, W. Jark, and G. Soullié, Appl. Phys. Lett. 71, 2557 (1997).

${ }^{9}$ S. Lagomarsino, A. Cedola, S. Di Fonzo, W. Jark, and C. Riekel, Notiziario Neutroni e Luce di Sincrotrone 3, 1 (1998).

${ }^{10}$ S. Di Fonzo, W. Jark, S. Lagomarsino, C. Giannini, L. De Caro, A. Cedola, and M. Müller, Nature 403, 638 (2000).

${ }^{11}$ A. P. Rizzato, C. V. Santilli, and S. H. Pulcinelli, J. Non-Cryst. Solids 247, 158 (1999); J. Sol-Gel Sci. Technol. 19, 811 (2000).

${ }^{12}$ G. E. S. Brito, C. V. Santilli, S. H. Pulcinelli, and A. F. Craievich, J. Non-Cryst. Solids 217, 41 (1997)

${ }^{13}$ M. Wormington, C. Panaccione, K. M. Matney, and D. K. Bowen, Philos. Trans. R. Soc. London, Ser. A 357, 2827 (1999).

${ }^{14}$ M. Wormington, D. K. Bowen, and B. K. Tanner, Mater. Res. Soc. Symp. Proc. 238, 119 (1992).

${ }^{15}$ L. G. Parratt, Phys. Rev. 95, 359 (1954).

${ }^{16}$ L. Névot and P. Croce, Rev. Phys. Appl. 15, 761 (1980). 